\title{
VACCINATION COVERAGE BEFORE AND AFTER INTRODUCING POLYVALENT VACCINES IN BITOLA
}

Domnika Rajchanovska ${ }^{1}$, T.Jovanovska ${ }^{1}$, V.P.Stojchevska ${ }^{1}$, G.R.Dimitrovska ${ }^{1}$, I.Filov ${ }^{1}$, I.Timovski ${ }^{2}$, M.Timovska ${ }^{3}$ ${ }^{1}$ University "St. Kliment Ohridski“ - Higher Medical School, Bitola, Republic of Macedonia. ${ }^{2} \mathrm{PHO}$ "Dr. Angelovska - Dr. Timovski", Skopje, Republic of Macedonia.

3PRD Skopje, Republic of Macedonia.

\section{Introduction}

- Active immunization in our country is compulsory against tuberculosis, diphtheria, tetanus, pertussis, poliomyelitis, measles, parotids (mumps), rubeolla, hepatitis $\mathrm{B}$ and hemophilus influenza tip B.

- Polyvalent vaccine, hexavalent and pentavalent, was implemented for the first time in august 2015 .

\section{Objectives}

The aim of the study is to evaluate the vaccination coverage of preschool children before and after introducing polyvalent vaccine in Municipality of Bitola.

\section{Materials and methods}

- The survey was conducted in the Office for preventive health care of preschool children in Bitola.

- In retrospective epidemiological study, vaccination data for the period from 2011 to 2017 was analyzed.

\section{Results}

98.24 - $99.46 \%$ of children were vaccinated with HB vaccine.

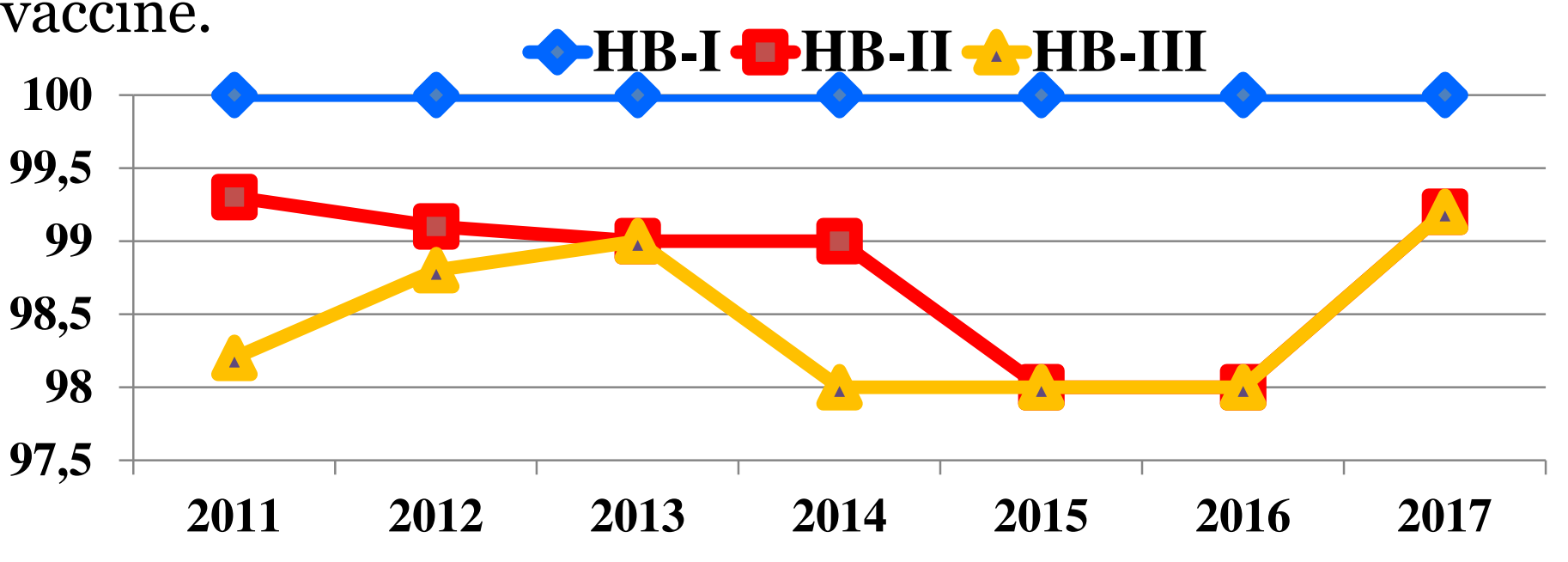

Vaccine against $\mathrm{HiB}$ in Macedonia was introduced in September 2008. Primary vaccination covered 91.53 98.00\% and revaccination covered $89,7-96.71 \%$ of children.

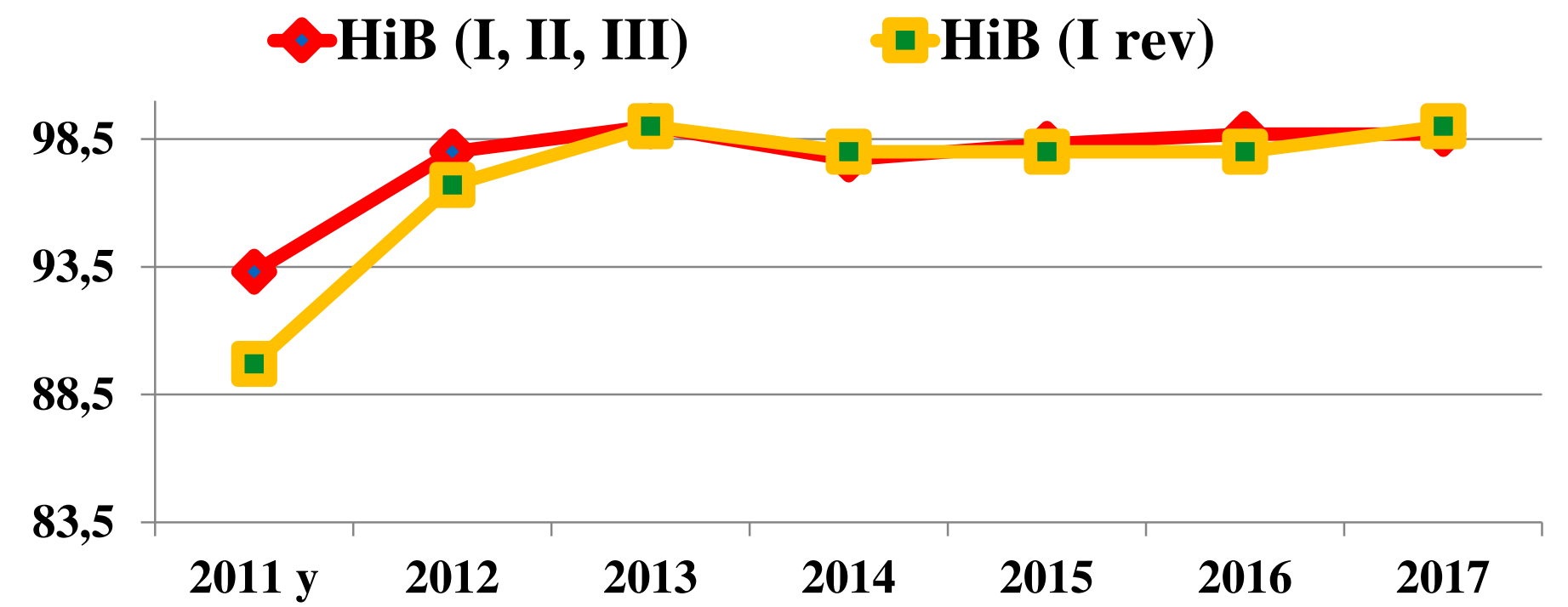

With primo vaccine DTP (three doses) 91.11 - 99.44\% of children were vaccinated, first revaccination covered 98.5399.44\%, and the second revaccination 93.34 - 98.66\% (since 2016 this vaccine is not mandatory).

\section{$\sim D T P\left(I\right.$, II, III) $-D T P\left(\right.$ I rev) $\_$DTP (II rev)}

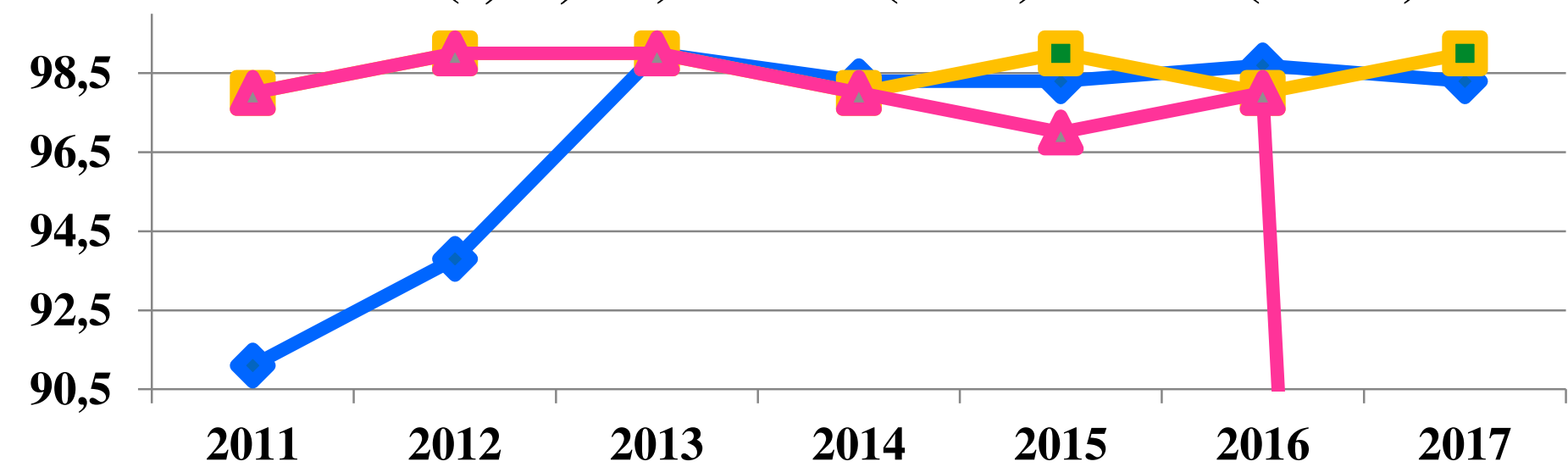

Primo vaccine OPV coverage rate is from 91.11 to $99.44 \%$, and revaccination coverage rate is $98.53-99.44 \%$ of the children.

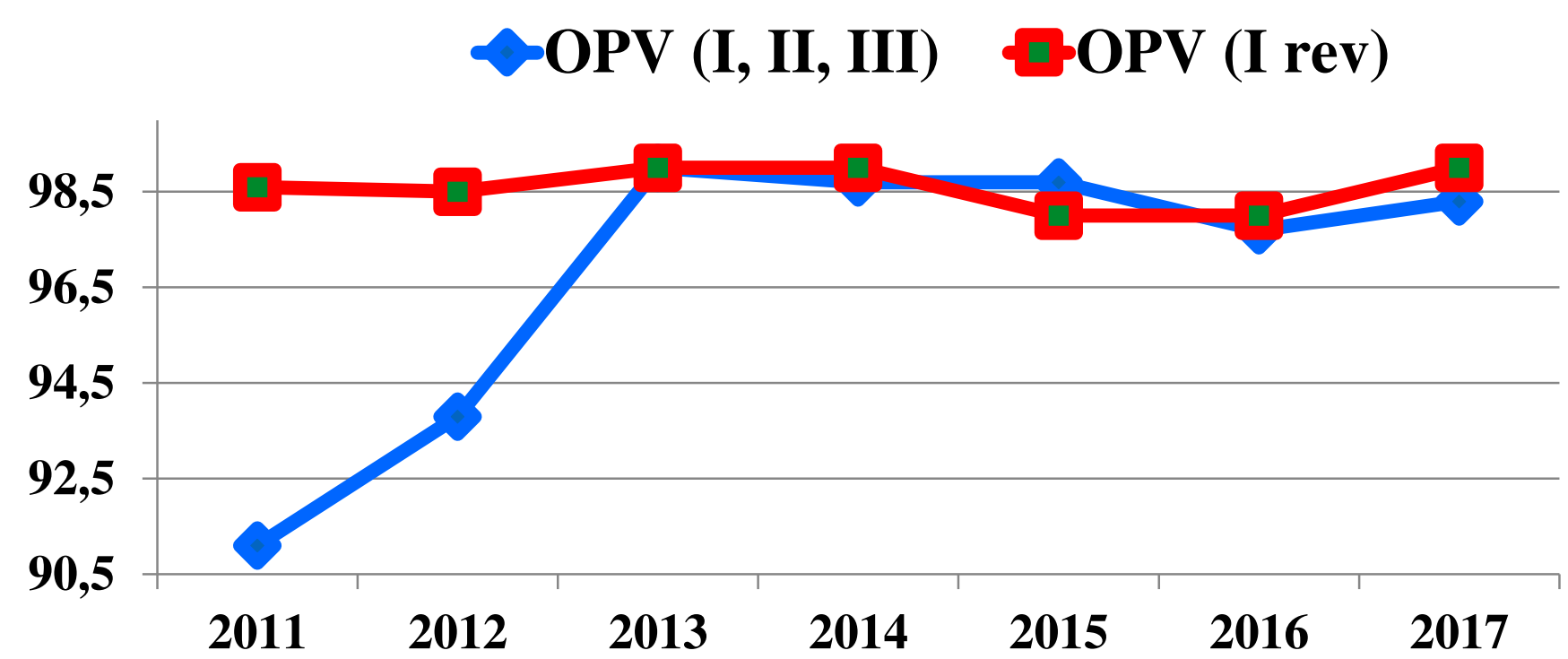

With vaccine against MMR, 98.97 - 100\% of children were vaccinated.

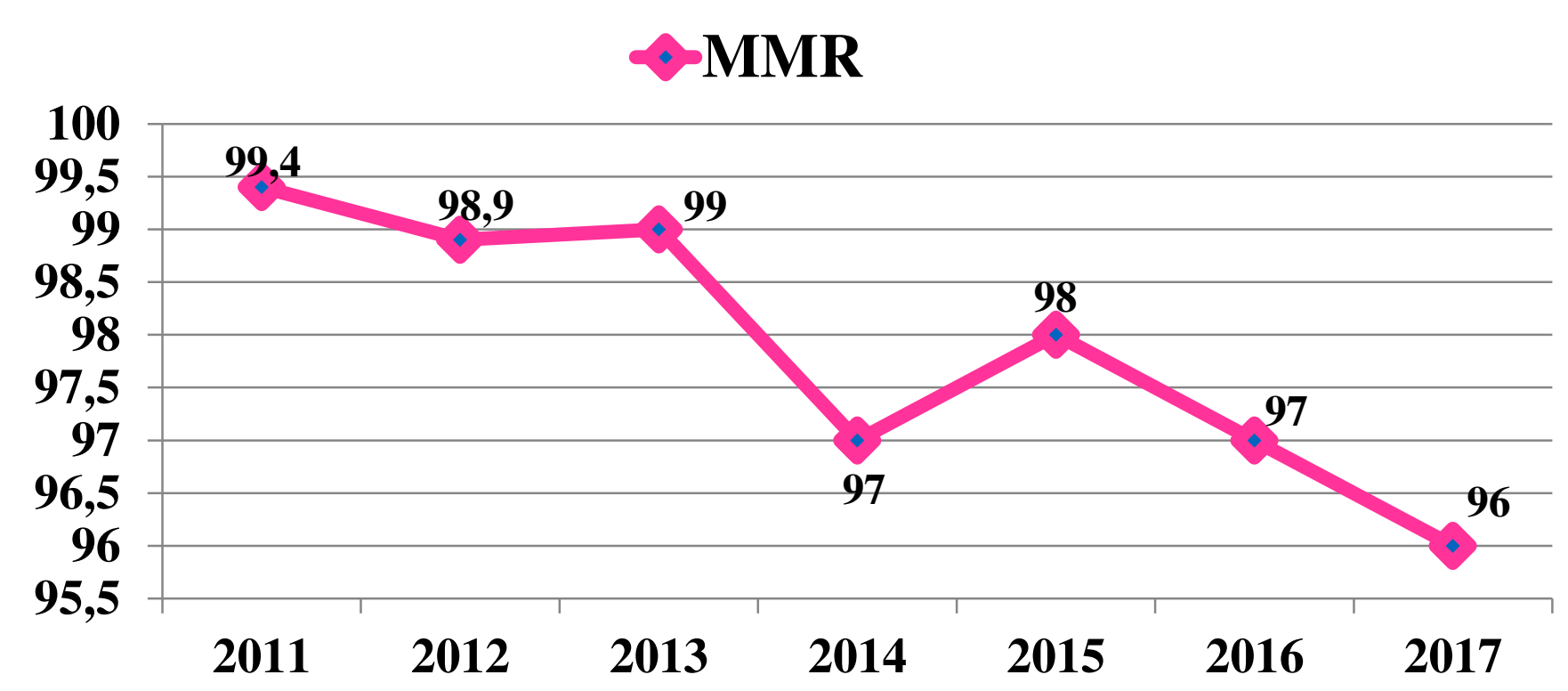

\section{Conclusion}

- In Macedonia the implementation of multivalent vaccines was successfully launched.

- The results of the study showed that the downward trend of vaccination coverage in recent years in Bitola decreased due to the introduction of polyvalent vaccines.

- Side effects of the vaccine are minimal, the benefits for the parents are reduced number of visits to the doctor, less stressful conditions and increased vaccination coverage.

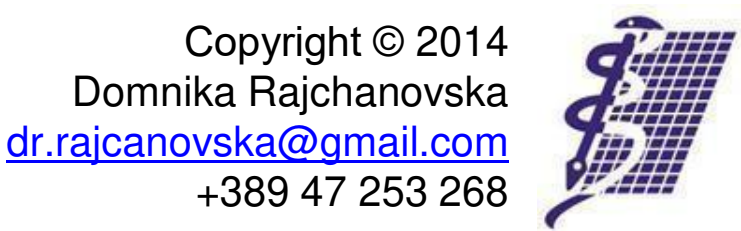

